
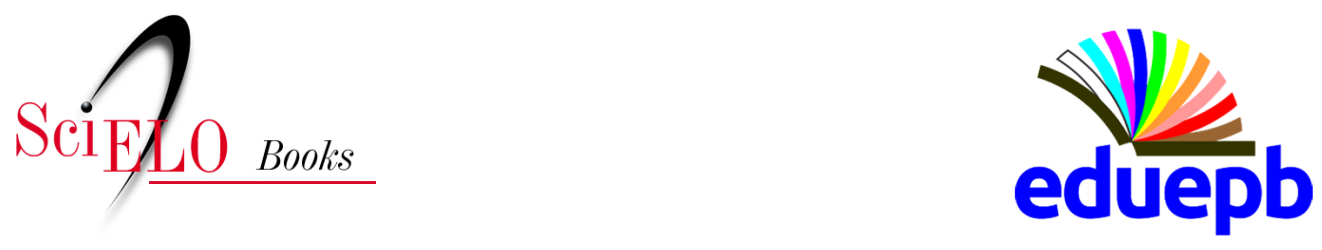

\title{
Influências e Legados \\ Adalberto Arruda - Celso Furtado queria mudar o Brasil promovendo a integração nacional
}

Milena Barros Marques dos Santos

\section{SciELO Books / SciELO Livros / SciELO Libros}

SANTOS, M. B. M. Adalberto Arruda - Celso Furtado queria mudar o Brasil promovendo a integração nacional. Interviewed: Adalberto Arruda. In:

SOUSA, C. M., THEIS, I. M., and BARBOSA, J. L. A., eds. Celso Furtado: a esperança militante (Depoimentos): vol. 2 [online]. Campina Grande:

EDUEPB, 2020, pp. 179-200. Projeto editorial 100 anos de Celso Furtado collection. ISBN: 978-65-86221-11-4.

https://doi.org/10.7476/9786586221671.0007.

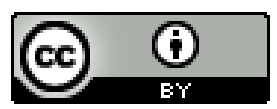

All the contents of this work, except where otherwise noted, is licensed under a Creative Commons Attribution 4.0 International license.

Todo o conteúdo deste trabalho, exceto quando houver ressalva, é publicado sob a licença Creative Commons Atribição 4.0.

Todo el contenido de esta obra, excepto donde se indique lo contrario, está bajo licencia de la licencia Creative Commons Reconocimento 4.0. 


\section{Adalberto Arruda*}

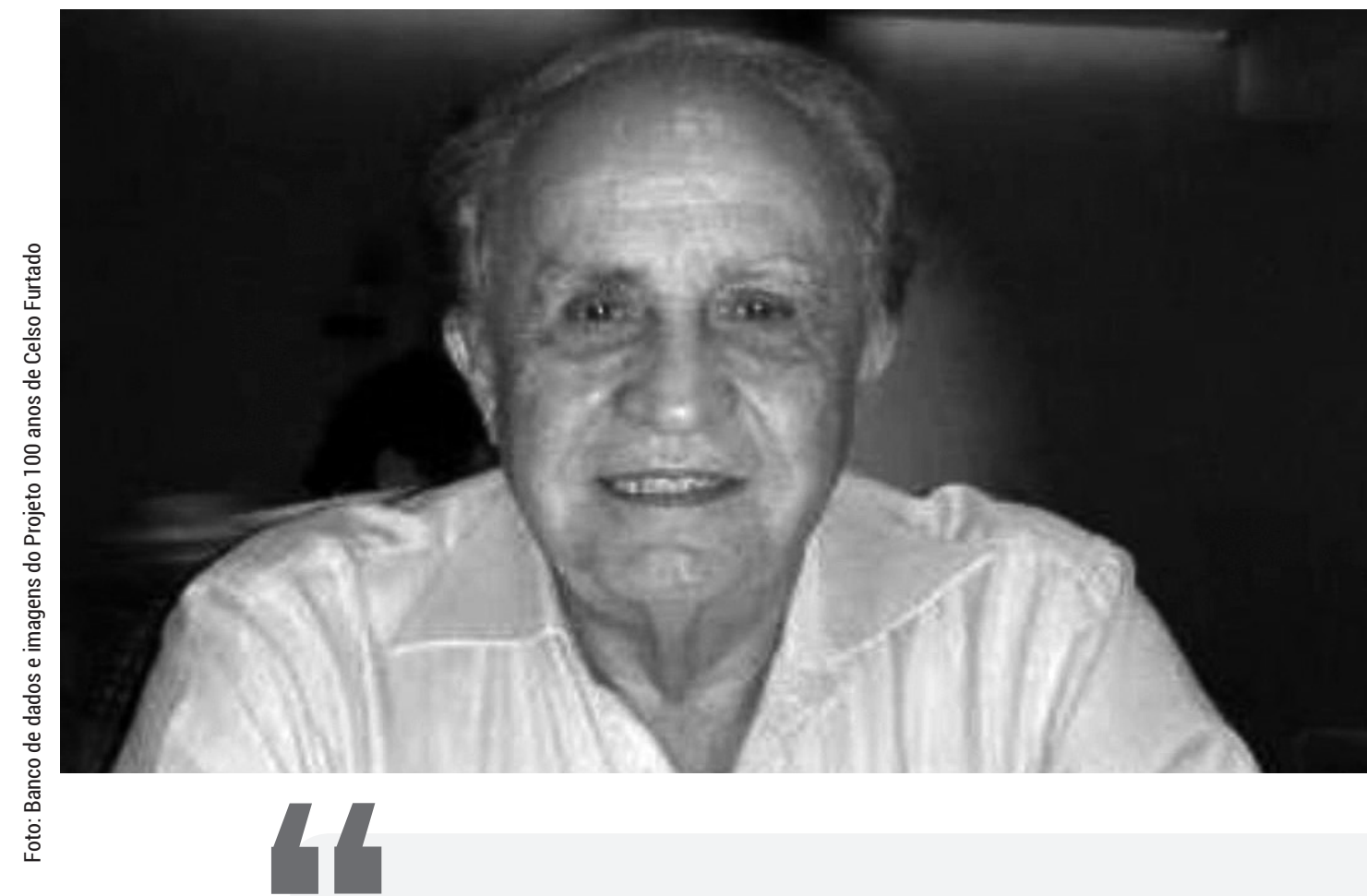

Celso tinha uma proposta de mudança que não era de violência; era um processo de mudança, digamos assim, democrática. Ele acreditava que era possível fazer a mudança social. A análise que ele fazia no grande documento Uma política de desenvolvimento econômico para o Nordeste é que o Brasil era um arquipélago econômico-social, que tinha regiões com níveis diferenciados de desenvolvimento, e que isso era ruim para a integração nacional. Era preciso solidarismo. Isso que nós chamamos hoje de solidarismo, Celso chamava de integração nacional, integração social e econômica, e dizia que essa integração só podia ser feita com uma ação forte governamental.

* Entrevista realizada em 07/11/2014, no contexto das atividades do Procondel (Sudene - UFPE), por Angela Nascimento, mestre em Ciência da Informação, e Fernando Weller, cineasta, doutor em Comunicação pela UFPE, professor e Coordenador adjunto do Departamento de Comunicação da mesma universidade, e cedida aos organizadores da Trilogia Celso Furtado: a esperança militante. 


\title{
Celso Furtado queria mudar o Brasil promovendo a integração nacional
}

\begin{abstract}
dalberto Arruda Silva' realizou, aos 25 anos, o que considerava ser Ao sonho dos jovens recém-graduados de sua época, início dos anos 1960: ingressar na Sudene. Formado em Direito e motivado pelo idealismo da chamada justiça econômica, o pernambucano foi selecionado, entre mais de 250 jovens, e participou do curso de Técnico em Desenvolvimento Econômico (TDE) ${ }^{2}$ da instituição. Dentre os professores, destaca Celso Furtado, superintendente da Sudene; Gilberto Freire; Aníbal Pinto Santa Cruz; Isaac Kerstenetzky; e Luiz Vasconcellos. A Sudene era forte administrativamente e ligada diretamente à Presidência da República. Sob a liderança de Furtado, tinha como objetivo promover a integração nacional e, por consequência, mudar o Brasil.
\end{abstract}

A proposta, recorda-se Silva, era de um processo de mudança democrática, não violenta; Celso Furtado enxergava o Brasil como um arquipélago econômico-social, com regiões em diferenciados níveis de desenvolvimento. A integração nacional seria social e econômica, e dependia de ação governamental forte para reverter a tendência de relações exploratórias entre economias fortes e fracas, com prejuízos para a região menos desenvolvida. Tratava-se de um projeto nacionalista, de grande sentido social, que galvanizava a juventude da época e defendia planejamento e, de certa forma, a estatização. Não pretendia acabar

1 Advogado (Faculdade de Direito do Recife - UFPE), Economista (UNICAP), Técnico em Planejamento e Desenvolvimento (Nível de Pós-graduação Especialização, Curso CEPAL/ BNDES/ Sudene em 1962). Atividades Profissionais: Sudene/Recife ( o8.1962 a 31.12.1964), Consultor de Empresas em Projetos Técnico-financeiros de Empresas, Assessoria em Direito Tributário e Incentivos Fiscais (o1.03.1965/Maio 1985); Professor Universitário por contratos temporário de trabalho (UNICAP e UFPB), Técnico da Sudene (reintegrado como anistiado político, de agosto de 1985 a Dezembro de 1990. Profissional liberal e assessor técnico da FIEPE (1992/96) e Diretor da Associação Comercial de PE (2003/2013). Pernambucano. Membro da União Brasileira de Escritores (PE) e articulista de jornais.

2 TDE - curso oferecido pela Sudene à maioria de seus técnicos, para que pudessem dispor de mesma linguagem sobre o desenvolvimento. Os técnicos eram profissionais agrônomos, advogados, médicos, engenheiros, arquitetos, entre outros. 
com o setor privado, e nem estatizar ou socializar toda a economia. Pretendia um tipo de experiência mista, semelhante ao que acontece atualmente na China.

A liderança técnica de Furtado também podia ser percebida nas reuniões do Conselho Deliberativo da Sudene (Condel), um órgão de decisões estratégicas de desenvolvimento econômico regional, com repercussão nacional, e um importante fórum político no país. Participavam das reuniões sete governadores (posteriormente nove), ministros da área econômica, representantes do Estado Maior das Forças Armadas, do Banco do Brasil e do Banco do Nordeste. O secretário do Condel, que preparava as pautas submetidas às deliberações, era o superintendente da Sudene, naquela ocasião, o próprio Furtado, que acumulava, também, o cargo de ministro do Planejamento. Silva participou de algumas reuniões do Condel, enquanto técnico da Sudene.

Em 1964, Adalberto Silva teve parte do sonho interrompido devido ao golpe militar. Celso Furtado foi exilado. Uma injustiça lamentável, na opinião do pernambucano, exilar um homem patriota, humanista, afável, que queria o bem de todos e do Brasil. Francisco de Oliveira, um dos assessores diretos de Furtado, foi preso. Muitos outros colaboradores foram presos, torturados, demitidos ou recolhidos, como ele mesmo, que ficou 15 dias recolhido, incomunicável, para responder a uma auditoria na Secretaria de Segurança Pública sobre os conteúdos ministrados aos municípios nordestinos em atividades de capacitação da Sudene. Meses depois, no final de 1964, foi afastado da instituição por "incompatibilidade ideológica para o exercício do serviço público". O retorno à Superintendência só ocorreu em 1985, com a Segunda Lei da Anistia, no período da redemocratização do país. Confira, a seguir, a entrevista concedida por Adalberto Arruda Silva aos pesquisadores Angela Nascimento e Fernando Weller, em novembro de 2014, no contexto das atividades do Procondel ${ }^{3}$.

(Milena Barros Marques dos Santos)4

3 O Procondel (http://procondel.sudene.gov.br/) foi o projeto de preservação e disponibilização do acervo do Conselho Deliberativo da Sudene Condel, período 1959 200o, realizado pela Sudene em parceria com a Universidade Federal de Pernambuco entre 2013 e 2016, e tinha como meta a preservação desse acervo e a universalização do seu acesso, coordenado pelo professor doutor Marcos Costa Lima e pela professora mestra Angela Nascimento.

4 Jornalista, Mestranda em Desenvolvimento Regional (PPGDR UEPB), Especialista em Gestão Pública, documentarista 


\section{Entrevista}

- Eu queria pedir ao senhor para que falasse um pouco da sua trajetória até chegar à Sudene, a origem do senhor, como é que foi a sua formação?

Olha, eu sou formado em Direito. Terminei o meu curso em 61 e logo em seguida achei por bem iniciar um curso de Economia. Prevalecia no meu entendimento e naquela época, de uma certa forma, um valor social de que a verdadeira justiça era a justiça econômica: ter acesso aos bens econômicos que permitisse viver com dignidade e bem estar. E esse era um assunto que a sociedade discutia muito bem, discutia isso na dimensão dos chamados 'ismos' da época, e atraía muito a juventude. Eu já trabalhava num escritório de advocacia e na área trabalhista, quando aparece o edital abrindo a oportunidade de trabalhar na Sudene. Me inscrevi, apresentei um trabalho. [Tinha] mais de 250 inscritos. Participamos de um curso de seleção e treinamento. Terminamos 27, dos quais 4 ou 5, aproximadamente, eram vindos de outros estados. Fui selecionado e foi desta forma que ingressei, atraído então pelo ideal de trabalhar na Sudene, que era uma coisa muito forte para os jovens que terminavam o curso superior naquela época.

\section{- O senhor é nascido aqui em Pernambuco?}

Sou nascido aqui em Pernambuco. Sou pernambucano, formado na Faculdade de Direito do Recife e fazia o curso de Economia na Universidade Católica de Pernambuco, na então UNICAP.

- Queria que falasse um pouco mais sobre a imagem da Sudene, como era a imagem da Sudene entre os jovens, entre os funcionários?

Olha, a imagem da Sudene era muito forte. Eu acredito que o grosso, a melhor parte da juventude universitária, sonhava trabalhar na Sudene. Eu preferi trabalhar na Sudene a ingressar na carreira do Poder Judiciário, do Ministério Público. A imagem social [da Sudene] era mais forte. Eu vivenciava o idealismo da chamada justiça econômica, aquilo também me motivava. Não era a auri sacra fames, a fome sagrada por dinheiro, que talvez o Poder Judiciário e o Ministério Público proporcionassem algo mais. Não seria muito mais, porque a Sudene já oferecia condições bem favoráveis de remuneração 
naquela época. Fui selecionado e pude trabalhar, então, no chamado Departamento de Assistência Técnica em Formação de Pessoal (DATFP). Participei de alguns programas, dos quais alguns me deixam a lembrança muito forte, como, por exemplo, um programa de assistência técnica aos estados e municípios. Eu tinha usufruído de conhecimentos naquele curso de desenvolvimento econômico, que foi um curso intensivo, conforme eu já disse. Começaram 94 e terminaram 27. Esse curso intensivo nos dava cadeiras de desenvolvimento econômico, de teoria do desenvolvimento econômico, tendo como professores Celso Furtado, Gilberto Freyre e Aníbal Pinto Santa Cruz, um chileno que era uma das maiores expressões, digamos assim, da escola cepalina latinoamericana. O presidente do IBGE, Isaac Kerstenetzky, na época, desculpa a pronúncia, também foi nosso professor, a exemplo de Luiz Vasconcellos, que era um técnico da FAO, da ONU, especializado em agricultura e abastecimento, que terminou ficando aqui no Nordeste e foi um dos responsáveis pela estruturação das centrais de abastecimento de todo o Brasil, que começaram aqui no Nordeste com a experiência da Sudene. Então, esse programa foi um programa forte, conforme eu dizia, onde eu pude participar de treinamento dado aos então secretários de prefeitura, que era um cargo, digamos, fixo, efetivo, estratégico para as administrações municipais daquela época, segundo a estrutura organizacional oficial vigente. Pude visitar várias cidades do interior de vários estados do nordeste: Bahia, Sergipe, Alagoas, Pernambuco, Paraíba, Ceará, Rio Grande do Norte, e ministrar aula de desenvolvimento econômico. Conto aqui uma particularidade: a minha função era dentro de uma programação, digamos assim, mais objetivamente técnica, ministrada pelo então Instituto Brasileiro de Administração Municipal - IBAM, dirigido por um pernambucano, simpaticíssimo e muitíssimo competente, Diogo Lordello de Mello. Ele era responsável pela parte técnica - legislação municipal. Foi integrada a esse curso, por solicitação da Sudene em parceria com o IBAM, a cadeira de Teoria do Desenvolvimento Econômico, com o seguinte conteúdo: o que é desenvolvimento econômico; filosofia do desenvolvimento econômico; diferença entre [desenvolvimento e] crescimento econômico, que implicava em busca de cidadania, de igualitarismo, de saúde, de educação para todos; o que era a pirâmide social; mudança social; o que é o estruturalismo. E aqui, agora, eu faço uma confissão: eu fui questionado num inquérito policial 
para prestar conta dessas 'perigosas aulas' de então dita comunização, que não tinham nada disso; era Teoria do Desenvolvimento que eu passava. Paguei o preço por essas coisas. São coisas que a gente se lembra e que a gente se orgulha, porque acredito que foi um serviço que prestei com o maior esforço, e pelo conteúdo das coisas que me eram passadas e que eu transmitia, de grande validade para a cidadania, para a educação da sociedade... Motivação e eficientização dos serviços públicos, que receberam entendimento equivocado, deformado, obscurantista das autoridades de um governo autoritário, que sucedeu a Celso Furtado, na Sudene.

- Eu queria que o senhor falasse mais sobre esses dois momentos: o momento anterior ao golpe militar de 64, e o momento do golpe militar. Qual foi o impacto para a instituição e para essa concepção de desenvolvimento do Nordeste?

Olha, eu acho o seguinte: a Sudene dita de Celso Furtado deve ser analisada em separado em relação a Sudene das suas demais fases. Eu diria que aquela era uma Sudene histórica. Alguns defendiam até que aqueles projetos dele ficassem na prateleira, porque havia ali, eu não diria tanto, uma formação de quadros internos que resistiram bravamente e seguiram, apesar das limitações impostas pelo poder autoritário, procurando fazer o possível, o melhor, para cumprirem a sua missão institucional. Mas diria que naquela época tinha um ethos diferenciado. Você veja que Celso tinha uma liderança muito forte. Era um homem que já tinha 12 anos de experiência internacional em órgãos das Nações Unidas e tinha uma inteligência excepcional. Posteriormente, veio a ser cogitado para o Prêmio Nobel de Economia e foi professor, durante 21 anos, da Sorbonne. Isso já é uma referência importante para dizer quem era Celso. "Formação Econômica do Brasil' é um dos livros sapienciais e mais importante da teoria econômica, produzida no Brasil. Celso tinha uma liderança muito forte, e recebeu apoio daquilo que havia de mais progressista dentro da sociedade brasileira. Ele era articulado com intelectuais, sobretudo com aqueles que formavam a linha de esquerda, que o apoiavam bastante. A gente sabe que naquela época o mundo vivenciava muita mudança, muita contradição. A gente diria que era a época dos 'ismos', da descolonização, digamos assim, na África. Era a época em que o socialismo soviético procurava apresentar ao mundo o que ele pretendia: uma capacidade de competir com o sistema 
capitalista e oferecer progressos sociais econômicos, que, [como] depois se viu, era muito conflituoso todo esse processo. Mas, na época [o que] passava para a juventude era uma imagem de sucesso. Eu lembro, por exemplo, do livro 'Paz no Mundo', de Jorge Amado, que era um stalinista. Ele foi à União Soviética e voltou encantado. $\mathrm{Eu}$ acho até que exageradamente, apresentando a sociedade da então União Soviética como sendo uma sociedade extremamente avançada e com muitos progressos. Não diria a perfeição; não era essa a expressão que ele usava, mas galvanizava a juventude. Era a época em que Cuba, o governo de Fidel Castro, então revolucionário, tinha derrubado, aqui bem perto de nós, a ditadura sanguinária de Fulgêncio Batista... Isso também se discutia muito no Brasil. Aqui também se pleiteava reformas sociais. Nós tínhamos grandes oradores, digamos assim, que defendiam o socialismo. Cito aqui um que é meu parente, Francisco Julião. Vocês são jovens, mas Francisco Julião era um homem que assumia, digamos, a tribuna num comício público (não havia televisão) e discutia as questões sociais nacionais. Eu dou um exemplo, dentre outros. Ele, como marxista que era, moldava o discurso em cima da teoria da luta de classe. Debatia, por exemplo, a questão das prostitutas: "Brasil, 500 mil prostitutas, todas elas filhas de operários e camponeses." Aí ele desenvolvia toda uma tese: "aquela jovem que entrou na prostituição fora a moça filha de um camponês que veio trabalhar numa família da cidade, que foi, às vezes, estuprada pelo patrão, pelo filho do patrão, e volta para casa grávida e o pai a expulsa de casa. Essa moça termina os seus dias na periferia das cidades de médio porte, de grande porte, como prostituta, extremamente explorada, com uma vida muito curta, entrando até na criminalidade." Era isso que se discutia em palanque, coisa muito diferente da temática discutida nos palanques de hoje. A juventude era galvanizada, correta ou incorretamente por esse tema, e eu estava nesse contexto. Celso tinha uma proposta de mudança que não era de violência; era um processo de mudança, digamos assim, democrática. Ele acreditava que era possível fazer a mudança social. Reclamava, no grande documento que produziu, "Uma Política de Desenvolvimento para o Nordeste" que o Brasil era um arquipélago econômico-social, com regiões com níveis diferenciados de desenvolvimento, e que isso era ruim para a integração nacional. Era preciso solidarismo. Isso que hoje nós chamamos solidarismo, Celso chamava de integração nacional, que era a integração 
social e econômica. Essa integração só podia ser feita com a ação forte governamental. Dizia que sendo o Nordeste uma economia fraca e o centro-oeste uma economia forte, as relações econômicas entre elas tendia a assumir caráter de relações exploratórias, com prejuízo para a região menos desenvolvida. A mudança, então, só seria possível com ação estatal forte. E fez uma análise muito consistente, muito bem fundamentada estatisticamente, analisando o período 48 a 56. As estatísticas disponíveis já diagnosticavam uma diferença de nível de renda per capita nordeste-sudeste de 1 para 2, e, fazendo as progressões, considerando a taxa de crescimento, a do Nordeste era muito inferior. Então, o seu projeto era um projeto nacionalista, era um projeto de grande sentido social, que galvanizava a juventude da época. Foi nesse projeto que eu embarquei e me envolvi. Dei o máximo de mim até onde pude. Fiquei na Sudene até 31 de dezembro de 64, quando fui afastado, segundo o meu processo, por "incompatibilidade ideológica para o exercício do serviço público”, por determinação do então general Cordeiro de Faria.

- Eu queria lhe perguntar como é que foi esse processo do afastamento, e qual foi o impacto do golpe militar na vida institucional da Sudene, cotidiana e institucional.

Olha, eu acho que foi muito forte. O projeto de Celso na Sudene era um projeto de mudar o Brasil promovendo a integração nacional. Ele, além de superintendente da Sudene, foi também o primeiro ministro de Planejamento do Brasil, que elaborou o primeiro Plano Trienal de Desenvolvimento. Celso foi convidado pelo governo parlamentarista e ficou lá, aproximadamente, um ano, acumulando as atribuições também de superintendente da Sudene, que, na época, era uma instituição extremamente forte. Bom, basta dizer que era ligada diretamente à Presidência da República. Os chamados itens de recursos constantes do orçamento da Sudene não caíam em exercício findo; ficavam sempre disponíveis para aplicação no Nordeste. Essa era uma garantia que não havia para nenhum outro dispositivo, em nenhum outro orçamento brasileiro. E nós tínhamos, também, o nosso Plano Trienal, que foi o primeiro Plano Diretor, aprovado em 1961 e, também, elaborado por Celso Furtado. Veio o sistema de 1964. Em relação à Sudene eu acho que foi muito violento, muito forte. Primeiro, a expulsão de Celso Furtado para o exílio, que foi uma injustiça lamentável. Ele era um patriota, um homem que 
queria o bem do Brasil, um homem afável, um homem humanista, que queria o bem de todos... Prisão de Francisco de Oliveira e Celso Furtado expulso do país. Muitos dos seus colaboradores também foram presos. Eu quero dizer que eu também participei, fui recolhido em certo momento, 13 de agosto de 1964. Em meu birô de trabalho fui procurado por dois beleguins da Polícia Civil dizendo que o general Salvador Batista do Rego me convocou para comparecer a uma audiência na Secretaria de Segurança Pública, na Rua da Aurora. Permaneci lá 15 dias incomunicável, inclusive com os meus pais, para responder a uma audiência. Mas não apenas eu. Diversos colegas responderam a questões controversas. Eu fui acusado de comunizar a região Nordeste com aqueles cursos pelos municípios. A Sudene, que mexeu com muita coisa trazendo ideias novas, defendia a teoria do planejamento e uma certa forma a estatização. Celso montou 13 sociedades de economia mista no Nordeste, porque ele não pretendia acabar com o setor privado e nem estatizar toda a economia, e nem tampouco socializar a economia. Ele queria um tipo de experiência mista, como hoje mais ou menos acontece na China. Então criou 13 sociedades de economia mista para a eletrificação rural do Nordeste; perfuração de poços; para a pesca (Penesa do Nordeste S/A) ...Incrível! A tese era que o setor privado não tinha a capacidade técnica, econômica e organizacional para exercer esses trabalhos e a sociedade não podia esperar. O setor público tinha que assumir essa responsabilidade, quem sabe, adiante podendo passá-las de retorno ao setor privado. Essas eram as ideias de Celso. E como ele era desenvolvimentista, tinha pressa. Organizava e se dedicava a essas sociedades em tempo integral, sem a preocupação de ganhar dinheiro. E não se viu em nenhuma delas acusação de corrupção, porque as pessoas se dedicavam, e repito, dentro um ethos que tinha como Celso o referencial. Celso tinha uma disciplina muito grande e conseguia passar isso para todos os seus liderados. Alguns especialistas, servidores da Sudene, para se integrarem com as universidades ministrando cursos, só faziam isso com a assinatura pessoal dele, para evitar abusos. Ninguém poderia, digamos, liberar a seu talante, entende? Repito, [havia] necessidade, por exemplo, na área de economia. Na Universidade Católica, a cadeira de planejamento chamava cadeira de fomento econômico, porque era assim que se chamava em Portugal salazarista. A palavra planejamento era uma palavra proibida, porque era a palavra que se dizia na União 
Soviética. Era um equívoco terrível! São conceitos completamente diferentes, que sociedades, mesmo capitalistas avançadas, já tinham incorporado. Mas nós estávamos atrasados para sequer nos situarmos no patamar de sociedades, digamos assim, referencialmente capitalistas na linguagem econômica. Havia um atraso econômico, tecnológico e social no Nordeste, entende? Então,

Celso dizia que o mais importante do que ter é ser, mais importante do que ser é construir, é fazer. Porque fazer é uma forma de ser. Ser e fazer estão conjugados, e ninguém tem valor essencial pleno se não for também um construtor.

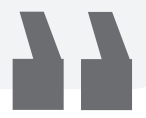

como eu ia dizendo, [sobre] esse projeto que era essencialmente desenvolvimentista, Celso dizia que o mais importante do que ter é ser, mais importante do que ser é construir, é fazer. Porque fazer é uma forma de ser. Ser e fazer estão conjugadamente, ninguém tem valor essencial pleno se não for também um construtor. Celso passava também essas lições. Pois bem, eu quero lembrar que a Sudene destinava sempre recurso para fortalecer o capital da Chesf, e, com isso, a Chesf poder ampliar a oferta de energia elétrica para a região. Celso dizia que era um insumo estratégico e era preciso se antecipar a demanda. O setor privado não tinha condição de atender a essa necessidade social, daí que o setor público tinha que ocupar esse espaço. Então [a Sudene] foi violentamente, digamos assim, agredida pelo sistema, que não compreendeu, embora, é fato, que alguns setores militares esclarecidos valorizaram a Sudene. Eu lembro que os generais que ocuparam a Sudene, já depois do governo militar, tiveram um comportamento respeitável, sem dúvida, embora num contexto global difícil e completamente diferenciado. Até porque, no dizer de alguns, a chamada "limpeza" já havia sido feita em 1964, quando foram demitidos muitos companheiros. Então foi muito forte. Mas eu faço aqui algumas confissões. O Celso não pertencia ao partido comunista, não pertencia a nenhum partido político, está certo, mas havia um núcleo do PCB [dentro da Sudene]. O PCB não tinha, naquela época, a [proposta de] ação de mudança pela violência, mas, sim, a partir de processos, digamos, democráticos, com participação no debate acadêmico, no debate pela mídia, e, sobretudo, no parlamento, de maneira firme e determinada. Mas esse setor dentro da Sudene não chegou a ser notado, não chegou no chamado Partido Comunista Brasileiro, mas foi muito forte a repressão dentro da 
Sudene. Digo porque a Sudene de Celso, por conseguinte, era aquela Sudene com aquele ethos, com aquela visão de querer a sociedade de economia mista, de construção, de dialismo, de unidade, de trabalho, de pensar no Nordeste no Brasil e no mundo também.

\section{- Eu não entendi, o senhor falou que não foi desmontado o quê?} Não, eu quero dizer que os integrantes do chamado Núcleo do Partido Comunista da Sudene foram presos individualizadamente, mas estruturalmente o pessoal não conseguiu trabalhar. Ainda remanesceram companheiros depois de 1964, ainda permaneceram alguns companheiros dentro da própria Sudene. Foram demitidos, alguns presos, torturados, e alguns até se suicidaram por sequelas de tortura... Dou aqui o exemplo de Rivadavia Braz de Oliveira, que saiu completamente desestruturado depois de uma tortura sofrida aqui nos espaços em que essas práticas miseráveis eram exercidas. Ele se suicidou atirando-se de uma ponte do Rio Parnaíba, apesar [de ser] pai de dois filhos. Tem exemplos, também, de outros colegas que se desestruturaram psicologicamente vítimas de tortura. A prisão em si já é uma violência, mas a prisão num estado ditatorial é simplesmente uma coisa apavorante, porque você fica à mercê de qualquer beleguim torturador, cruel e endoidecido, fica à mercê dessas figuras monstruosas.

- O senhor disse que assistia algumas reuniões do CONDEL, o senhor ia na qualidade de técnico? E assim, como é que eram? Olha, a estruturação da Sudene foi muito feliz, de uma certa forma, quando criou o chamado Conselho Deliberativo (Condel), que era o órgão que tomava as decisões estratégicas para a Secretaria Executiva cumprir. O superintendente da Sudene era o secretário do Conselho Deliberativo, o homem que preparava as pautas e as matérias técnicas que eram submetidas às deliberações do Conselho. Esse Conselho, sem dúvida, passou a se constituir no segundo maior fórum político do país, depois do Congresso Nacional. Veja que ele era formado por nove governadores, o estado maior das forças armadas, ministros da área econômica, o Banco do Brasil e o Banco do Nordeste. Ali eram tomadas grandes decisões de interesse do desenvolvimento econômico regional, com repercussão nacional. Era muito bom para a região a existência do Condel. Lamentavelmente a Sudene passou a não dispor, como não dispõe mais hoje em dia, das reuniões desse 
Conselho. Preparavam-se as matérias já bem negociadas e, sob a liderança técnica de Celso, elas eram apresentadas ao Conselho. Era um órgão técnico da magna importância e de grande sentido para o que foi a Sudene da época de Celso. Era um verdadeiro poder que se contrapunha ao poder de Brasília. Porque o Nordeste, conforme os estudos do próprio Celso, era menos desenvolvido e transferia recursos para a região centro sul. Segundo os diagnósticos, nós tínhamos limitações de recursos naturais: $2 / 3$ do Nordeste é cristalino e na região semiárida a precipitação pluviométrica é baixa e irregular. Em algumas regiões chove apenas 600 milímetros por ano, mas às vezes esses 600 milímetros caem em um, dois meses, e a gente fica dez meses sem chuva. E os solos também não são solos profundos; também são em grande parte cristalino. E na região da mata, também, há muitas limitações de qualidade de solo. Muito bem, se estima que naquele período de 1948 a 1956, segundo os estudos do próprio Celso, o Nordeste transferia, por mecanismo cambial, cerca de 24 milhões de dólares para apoio e desenvolvimento do centro sul do país. Mas esse não era o único mecanismo de transferência de renda do Nordeste para o sul, porque nós éramos superavitários na balança comercial, e esse superávit ficava com o governo. Ele utilizava para fazer importação de máquinas e equipamentos, ou de insumos que eram drenados para a região centro sul. Vamos mais ainda: o câmbio na época era câmbio diferenciado. Você tinha uma taxa de câmbio para importação de máquinas, uma taxa de câmbio para turismo, uma taxa de câmbio para importação de bens e consumo. A importação de máquinas era extremamente subsidiada, e esse subsídio ficava, obviamente, naquela região onde estava sendo implantado os novos núcleos de desenvolvimento industrial do país. Nós aplaudimos esse processo de desindustrialização da região Sul. No Nordeste temos, também, um núcleo de indústria forte. Esse núcleo era considerado por Celso essencial para o nosso processo de desenvolvimento, tanto para equilibrar o país, como, sobretudo, para gerar emprego. A gente hoje questiona: a indústria gera pouco emprego. Mas ela tem um efeito multiplicador muito grande na área de serviços. Na área de desenvolvimento da tecnologia a indústria tem efeitos, digamos assim, como os forward linkages de que falava Hirschman, record linkages and forward linkages, os efeitos para trás, no sentido de adquirir matéria-prima regional e fomentar, digamos, a produção de matéria-prima regional, inclusive sob a orientação tecnológica da 
própria indústria; e os efeitos para frente, no que tange a oferta de bens essenciais à comunidade, no transporte desses bens e outros efeitos para frente, exceto na prestação de serviços complementares: vigilância, alimentação, transporte, consumo, renda, efeito multiplicador, etc.. Por conta disso ele propunha transferência, via os Planos Diretores, de recursos do orçamento para compensar essas perdas, que Celso fundamentava estatisticamente de forma irrespondível. Estatísticas que tinham por força da sua verificabilidade apoiamento no Congresso Nacional.

\section{- O senhor saiu em 64?}

Eu saí da Sudene em 64.

\section{- Depois da Sudene qual foi a atividade?}

Olha, eu vivi fora do estado de Pernambuco. Tentei montar aqui um escritório de consultoria jurídica e também na atividade econômica, mas dois dos meus sócios tiveram 48 horas para deixar a cidade, porque uma autoridade do sistema autoritário disse que não poderia garantir pela segurança física deles, tendo em vista a ação dos militares. Eu quero dizer que isso é o espaço das ditaduras. A gente quando vive da democracia não vive isso. Entendeu? Podia até declinar o nome dessas pessoas: um era o Ulrich Hoffmann e o outro Natanias von Shosten, que também tinham sido dos quadros da Sudene. Eles tiveram 48 horas para deixar o Recife e o fizeram assustados, porque suas vidas estavam em risco. Também fui desaconselhado a deixar o Recife, mas terminei deixando. Fiquei dois anos e meio em São Paulo, trabalhei em Manaus, e trabalhei, também, no Rio Grande do Sul. Esse período foi muito bom num certo sentido. Dessas coisas todas reuni boa experiência. Trabalhei na Honda, em Manaus, e depois voltei e me instalei aqui em Pernambuco. Eu não me interessei em retornar ao serviço público na primeira Lei de Anistia, mas na segunda eu resolvi aderir e aceitar o processo. Retornei, juntamente com diversos outros companheiros, na segunda Lei da Anistia e tive a honra de participar da Sudene por mais nove anos, atuando, ao todo, quase dez anos e pouco.

\section{- E como foi essa volta?}

Essa volta se deu, repito, com a segunda Lei da Anistia, em 1985, já com a redemocratização. Eu voltei para o cargo que [já] tinha ocupado 
antes, de técnico em desenvolvimento. O que é um cargo de técnico de desenvolvimento? Celso criou uma espécie de tropa de choque para o cargo de técnico de desenvolvimento. Eu tinha uma carteira especial que me dava poderes para solicitar informações a qualquer repartição pública estadual ou federal, de natureza estatística, portando-se como técnico em desenvolvimento. Eu guardo comigo essa carteira ainda como uma recordação. Então, nós pertencíamos a esse quadro. Eu retornei , mas logo depois esse quadro foi transformado. Tive a oportunidade de participar de muitas atividades com a experiência que pude reunir trabalhando para o setor privado e, também, para o magistério. [Pude] oferecer a minha contribuição complementar dentro de um contexto diferente, já na fase da democracia restaurada no Brasil, que foi para mim um motivo de honra e de satisfação, tendo me aposentado em 1992.

- Como é que o senhor avalia a atuação da Sudene nesse período de redemocratização até os anos 90 ?

Olha, como sabemos, o setor público brasileiro, nesse período de governo ditatorial e de redemocratização, não chegou a receber aquele mesmo tributo de respeito, de apoiamento que tinha na época de Celso Furtado. Conforme eu dizia, a proposta do Celso tinha muito de estatizante, mas reservando o seu espaço para o setor privado também desempenhar a sua função, reconhecendo a eficiência e a eficácia desses dados do setor privado. E repitamos: sempre preocupado com as soluções pacíficas dos problemas e dos conflitos sociais, sempre democráticas e sempre pelo diálogo, um diálogo evidentemente objetivo, forçado, conclusivo. Não o diálogo pelo diálogo. Agora, digo que já nesse contexto diferente a Sudene exerceu um papel muito positivo também para a região. Lamentei muito a sua desativação em 2001, resultado de equívocos, alguns da própria Sudene, e outros, sobretudo, de pessoas de fora da Sudene. Equívocos da Sudene, vou dizer um deles: nós mantivemos por muito tempo uma parceria com a Sudam, que para nós foi muito desgastante. Eu dou aqui alguns exemplos: a Sudam aprovava projetos para o setor primário, digamos, projetos agropecuários, de mais de 300 mil hectares de terra, inclusive permitia, na época, a antecipação de recursos de incentivos fiscais antes da contrapartida de recursos próprios que o empresário deveria aportar para receber esse recurso. Não era procedimento da Sudene. Aqui os projetos do setor 
agropecuário, além de poucos, eram limitados em tamanho, bastante limitados. Se não me engano, inicialmente, eram 21 mil hectares; depois caiu para 12 mil hectares. E eram poucos. Nós pagávamos o preço de sempre, no Congresso Nacional, termos de apoiar, digamos assim, as propostas da Sudam. Eu recordo aqui uma atribuição que o superintendente me deu, certa vez, de ir a uma reunião em Belém do Pará. Sudene e Sudam juntas. Quando eu fiz a exposição do que eram as nossas diretrizes e as nossas medidas em relação às precauções para se administrar incentivos fiscais com mais rigor, com mais cuidado, para evitar qualquer desvio, eu fui tremendamente incompreendido e criticado pelo pessoal, sobretudo pelos empresários presentes. Senti até um clima de, mais do que anismitosidade, quase de ameaça, e resolvi sair de Belém do Pará um pouco às pressas, preocupado com a minha segurança pessoal. Eu relatei esse fato ao superintendente. Não obstante a isso, mantivemos a parceria que, em meu ver, foi prejudicial para a nossa imagem. Houve fenômenos desse tipo que pagamos um pouco pelo pecado dos outros. $\mathrm{O}$ grande erro do presidente Fernando Henrique Cardoso foi desativar a Sudene. Fez isso em cima de relatórios precipitados. Eu assisti uma coisa terrível na época. Foi um daqueles críticos da Sudene, o deputado federal José Pimentel, aliás, senador José Pimentel. Então do quadro do Banco do Nordeste que fez aqui essa confissão, digamos assim, vergonhosa. Quero lhes dizer que quando nos encontramos, que ele me estendeu a mão, e eu fiz questão de negar um aperto de mão a ele, ostensivamente.

- O senhor acha que havia também uma espécie de manipulação da opinião pública, de campanha negativa em torno da Sudene? Enfim, atendendo a interesses políticos da época.

Eu acho que sim. Os recursos eram limitados. Eu não trabalhava na área de incentivos fiscais; trabalhava numa outra área, mas acompanhava, porque se discutia muito [essas questões] dentro da Sudene. Sem dúvida isso existiu. É certo que os recursos eram limitados. Não atendiam a todo mundo. E de uma certa forma alguns grupos se insinuaram muito, de maneira muito forte, para utilizar incentivos da Sudene aprovando um, dois, três projetos... Havia a proposta dos técnicos da casa, que para cada grupo empresarial só se podia aprovar um projeto, e, tendo ele concluído esse projeto com sucesso, poderia se apoiar um segundo. Essa diretriz do aconselhamento não foi 
acolhida pela alta direção da casa. Isso foi ruim para a imagem da Sudene também, entre outros fatores.

\section{- O senhor voltou aqui foi?}

Eu voltei aqui em 1985, depois da segunda Lei da Anistia.

\section{- 1985. Como era esse prédio em 1985?}

Olha, esse prédio em 1985 já estava aqui. Funcionavam aqui algumas outras repartições. Não só do Banco do Brasil, [mas] repartições internacionais também. Mas, digamos, $70 \%$ [do prédio] eram ocupados pelos quadros da Sudene. Está certo? Eu quero dizer que a Sudene tinha uma estrutura muito forte. Ela tinha escritórios em todos os estados do Nordeste e a proposta inicial era, realmente, constituir-se num setor, numa sociedade de economia mista. Todas elas [sociedades de economia mista criadas ela Sudene] tinham sede aqui no prédio. Muitas delas foram desativadas, ou quase todas foram desativadas pelo governo autoritário. Mas havia muita efervescência e muita modificação na casa. Havia também muitos equívocos e muita frustração. Eu, por exemplo, faço aqui um depoimento. Eu ia ao refeitório da casa de camisa e gravata e os colegas, às vezes, vestidos descuidadamente, arrastando sandálias japonesas pelos corredores. Fui criticado pessoalmente, pela minha vaidade de querer andar de gravata dentro de uma repartição, quando aqui se devia, pelo clima, se trabalhar com maior liberdade. Eu digo: "vocês jamais me encontrarão aqui pelos corredores tomando um cafezinho numa xícara de plástico e muito menos como tu estás aí, com a barriga de fora e arrastando uma sandália japonesa." Disse a eles: "jamais." Eu era assessor do superintendente. E isso aconteceu também em incidentes, evidentemente, que foram poucos casos como esse que eu estou contando. Na generalidade, o comportamento era respeitoso e produtivo, dos companheiros da casa. Mas como eu recebi esse tipo de provocação e acinte, nessa oportunidade acho que devo fazer também esse depoimento, porque isso também existia.

- Como é que o senhor avalia a questão do desenvolvimento regional nesse momento atual? E até fazendo, também, uma avaliação da Sudene hoje.

Eu acho o quadro muito complexo. Eu lhes digo que eu não tenho muita clareza. Entendeu? Eu acho que nós temos ainda o problema 
do desenvolvimento regional, as carências especiais da região. Eu participei do grupo de trabalho da Sudene na Assembleia Nacional Constituinte, em 1988. Nós fizemos, ao meu ver, um bom trabalho, com a sistematização dentro do texto constitucional das diretrizes de se promover a redução das desigualdades regionais, e, inclusive, a inserção de instrumentos para a redução dessas desigualdades, com a hipótese de subsídio. Tudo isso está na Constituição. A sistematização das macrorregiões está na Constituição, em grande parte pelo trabalho que era dirigido pelo meu saudoso companheiro Antônio Carneiro Leão, de cuja equipe eu fiz parte trabalhando em Brasília. Agora, conforme eu ia dizendo, essa necessidade atual é complexa. Nós precisamos, realmente, de um tratamento ainda diferenciado para, sobretudo, assegurar recursos do governo federal para os projetos estratégicos da região. É inexplicável e injustificável que um projeto como a Transnordestina ainda não esteja [concluído]. Considere que o Porto de Suape é um porto sem ramal ferroviário. É inadmissível! É quase impensável que um porto com a dimensão de Suape, os propósitos de Suape, não tenha ramal ferroviário. E nós estamos sem ramal ferroviário há quase 20 anos. Depois, para a privatização para o setor empresarial, isso é inestimável. É preciso um encaminhamento mais rigoroso para esse caso, como também para o da transposição de bacias [do Rio São Francisco], processo que está atrasado, tem retoques técnicos a serem realizados. Vamos dar um exemplo: Adutora do Oeste. Aqui no estado de Pernambuco, onde há cerca de 48 municípios que precisam da água do São Francisco para terem condições de estabilidade para o abastecimento humano de suas populações... Tudo isso está atrasado, inexplicavelmente, e a Sudene sem força para agir, inobstante a boa vontade e ação, às vezes desesperada, dos superintendentes. Os governadores também passaram a assumir posições, digamos assim, conflitantes, cada um defendendo a brasa para a sua sardinha, querendo a promoção pessoal dos seus estados, perdendo a visão regional. Isso que não acontecia na época de Celso Furtado, tanto pelo contexto político como pela liderança que Celso tinha entre os governadores. E essa divisão, essa posição que, como é que a gente poderia dizer, fisiológica desses governadores, impede que os grandes projetos regionais tenham o tratamento adequado, com prejuízo para todos os estados. Esse é um contexto político. 
- Quais são as condições que o senhor imagina para que se retome essas condições dos anos 6o, de Celso Furtado? O que falta hoje para que a gente tenha um projeto semelhante?

Olha, eu tenho amigos que acham que o projeto Sudene já acabou e que ela deveria ser colocada na prateleira para ser julgada pela história. O contexto é outro, diferente. Passou a época dos 'ismos', aquela época, digamos assim, de uma utopia social, que hoje não se vive mais. Nós estamos vivendo uma época diferenciada, de economia virtual, por exemplo, que catequiza os jovens pelo inusitado da tecnologia, como se isso fosse a solução dos problemas materiais do mundo, quando em meu ver não é. Os grandes problemas materiais do mundo ainda são alimentação, energia, meio ambiente, e água, fundamentalmente. Pensar que 800 milhões de pessoas estão no mundo morrendo de fome, e que é preciso ainda produzir alimentos... Água é o que falta em São Paulo, falta no Nordeste e no mundo inteiro [temos] guerras por água. As denúncias de que no Oceano Pacífico se formam ilhas de resíduos plásticos de milhões de quilômetros quadrados, assustam. De vez em quando se pesca uma baleia cachalote... O Instituto de Desenvolvimento da França, num Congresso que houve há pouco, tomou conhecimento [que], no Equador, foi pescada uma baleia com 20 quilos de plástico no estômago. E o albatroz levando, no bico, tampas de garrafas de plástico para alimentar os seus filhos? ... Quando se abre a barriga de um filhote de albatroz na Ilha de Galápagos está cheia de tampas de garrafas plásticas... O mundo vive esses problemas e nós não podemos nos perder na metástase desses problemas virtuais, esquecendo dos problemas reais da sociedade. A sociedade vive isso. Estamos num contexto diferenciado. Essa é a minha visão do mundo.

- Então, o senhor discorda de quem acha que a Sudene não ia ficar...?

Eu acho que a Sudene histórica de Celso coube naquele momento. Era uma proposta correta, chamada, digamos assim, de Fantasia organizada, como o próprio Celso a chamou. Depois, ele publicou um outro livro onde a chamou de a Fantasia desfeita. Mas aquela fantasia organizada eu acho que deve ficar na prateleira para ser estudada. Mas, convenhamos, também, ela teve sentido no seu contexto histórico, onde podia caber com uma força que realmente tinha, e que poderia ter sido maior, não fora o obscurantismo e o egoísmo, que 
são componentes da personalidade humana, e em especial do sistema que eu chamo auri sacra fames, que é a fome sagrada pelo dinheiro.

- Quando o senhor vem a esse [prédio]...

Olha, devo dizer que a chamada Sudene histórica que eu vivenciei com aquela força da juventude, com aquela força que o americano poderia dizer, no coração selvagem da vida, aos 25 anos, não era aqui, era no outro prédio. Mas já retornando na segunda Lei da Anistia, quero dizer que esse prédio foi feito na época do governo autoritário, sem dúvida com propósitos respeitáveis, mas não sei se corretamente. A visão era para ter grandiosidade, ter expressividade, a monumentalidade de um castelo. Entrei aqui com muito respeito. É um prédio, é certo [feito], pela seriedade dos quadros que aqui encontrei, das pessoas que aqui estavam, pretendendo fazer o melhor, cumprir a missão institucional da casa.

- Doutor Adalberto, veja só: esse esvaziamento da Sudene passa pela ausência dos antigos diretores... porque depois disso começou o Pró-Nordeste, o Pró-Terra... começaram esses projetos todos determinados pelo governo federal, e a Sudene apenas fazia o papel de mediador, talvez. É como se ela não tivesse decidindo mais, não tivesse a interlocução dos pares dentro do Conselho... Seria isso?

É, a professora Angela levanta essa questão de projetos que vem de fora para que a casa os absorva e os conduza. Alguns, com certa aderência, digamos, regional, mas precisando receber, por parte da casa, já que essa é a sua missão, o seu detalhamento, o seu aperfeiçoamento, a sua exata adequação... projetos esses que foram empurrados de Brasília para cá. Quando se enfraqueceu, o Conselho Deliberativo da Sudene era o quê? Era a concentração de poderes em Brasília. $\mathrm{O}$ ministro do Interior, o ministro da Integração Regional punha no seu Gabinete aquilo que deveria ser discutido aqui no Conselho Deliberativo da Sudene. Isso foi um verdadeiro crime, que eu não 
digo contra o Nordeste, mas contra o Brasil, porque desenvolver o Nordeste é desenvolver o Brasil: impedir que os problemas da região pudessem ser discutidos no Conselho Deliberativo, aperfeiçoados, e, sobretudo, aprovados para serem executados com maior motivação, com mais sentido de responsabilidade. Aquilo era ponto de honra para eles. Aquela questão de honra que estava no projeto original da Sudene quando os Planos Diretores eram elaborados e defendidos, isso, de fato, enfraqueceu o órgão. Sem dúvida, essa super concentração de poderes em Brasília enfraqueceu a região em prejuízo da ineficiência da instituição, em prejuízo dos interesses, repito, regionais e até nacionais.

- A Sudene acreditava que com a Constituição de 88, que o senhor participou ativamente, pudesse ter um papel maior, não é? Isso não aconteceu.

Verdade. Foi uma última tentativa de sistematizar as ações regionais, mas a Constituição Brasileira, chamada Constituição Cidadã, também trouxe fortalecimento para os estados e sinalizou para os governadores dos estados que eles podiam se afirmar isoladamente. Cada um procurou, de certo modo, defender a sua sardinha isoladamente, sem pensar no coletivo regional, com perdas para todos.

\section{- E hoje, como é que fica esse desenvolvimento regional?}

Olha, o quadro é complexo. Eu acho que Sudene ainda tem uma missão importante que são esses incentivos fiscais de redução de imposto de renda, ou incentivos relacionados com outros tributos que ela ainda pode administrar. Eu acho que a Sudene tem uma atribuição muito forte também na distribuição do Fundo Constitucional do Nordeste, que é administrado pelo Banco do Nordeste, e que tem que se adequar às prioridades regionais. Eu acho, entre outras coisas, o CREDAMIGO cobrava até pouco tempo uma taxa de juros muito alta, e isso não passava pelo Conselho Deliberativo da Sudene. Ora, o Conselho tinha representante também dos trabalhadores, trabalhadores no setor primário, secundário e terciário, e também dos empresários. Passasse isso no Conselho Deliberativo, os trabalhadores teriam estudado isso com mais vagar, levado o assunto a apreciação dos demais conselheiros e ajustado esse programa, assegurando benefícios adequados para esses segmentos social na utilização desse recurso, que é um recurso oficial, que o banco tem a custo zero, que é o recurso do Fundo 
Constitucional, Artigo 159, Inciso $\mathbf{1}^{\circ}$, se não me engano, letra $B$, letra $C$, da Constituição Federal. Recursos destacados do imposto de renda e do IPI, que são impostos federais, que se destinam aqui ao Nordeste. Precisam ocupar com mais força esse espaço, o que é difícil porque só através do Conselho Deliberativo que é possível se fazer. E o Conselho Deliberativo tem dificuldades de se reunir em virtude, digamos, do personalismo dos governadores, que a sociedade toda constata isso. Perde a região, e perde o estado, e o povo desses estados. É a minha visão. Certo?
Quando se enfraqueceu, o Conselho Deliberativo da Sudene era o quê? Era a concentração de poderes em Brasília. 0 ministro do Interior, o ministro da Integração Regional... cada um punha no seu Gabinete aquilo que deveria ser discutido aqui no Conselho...Isso foi um verdadeiro crime, que eu não digo contra o Nordeste, mas contra o Brasil.

- O Conselho de antes também tinha nuances, diferenças de partidos, e mesmo assim, havia coesão. Hoje, além desse personalismo de que o senhor falou, tem as diferenças partidárias, mas os conselheiros não têm aquele interesse comum e não enxergam mais isso como um fórum. $O$ que a instituição poderia fazer, na sua visão?

Olha, como está se podendo fazer, digamos assim, tem um pensador que diz: "resisti brava e dignamente, resisti", fazer o possível com dignidade como está se pretendendo fazer, e tentar avançar, serenamente, mas de forma firme, buscando ocupar esses espaços como esse, de melhor administração do fundo, de financiamento do FNE. Certo?

- Eu queria só fazer uma última pergunta: o que o senhor acha que deveria ficar para a história? Já que a gente está fazendo o registro histórico sobre a Sudene. $O$ que o senhor acha que deveria ficar, digamos, registrado nessa memória aqui, da Sudene?

Eu acho que um tributo de reconhecimento ao que foi a Sudene histórica de Celso Furtado. Foi um projeto especial, elaborado para o Nordeste e para o Brasil, no sentido de melhorar a sociedade brasileira, em primeiro lugar, com a maior integração nacional. E, 
também, buscando motivar as pessoas dentro de um ethos bem forte de objetivação com interesse de compromisso ético com os interesses sociais, única maneira de se mudar a sociedade. Porque é como diz José Saramago, o verdadeiro progresso não é o progresso material; é o progresso moral. E sem o progresso moral não haverá progresso material efetivo, ou satisfatório. Bom, era o que eu tinha a dizer, não sei se valeu a pena, mas... 